\title{
0 QUE SE DIZ DO QUE (NÃO) SE VIU? HIROSHIMA MON AMOUR
}

http://dx.doi.org/10.11606/issn.2237-1184.v0i31p86-99

Celina Maria Moreira de Mello ${ }^{\mathrm{II}}$

\section{RESUM0}

A Segunda Guerra mundial, em sua complexidade e dimensões, levou a uma reflexão sobre a (im)potência da literatura e das artes, interrogando os limites de sua representação em registros documentais e em obras de arte. Neste ensaio são comparados certos processos de construção das narrativas de Nuit et brouillard (1955), dirigido por Alain Resnais, com roteiro de Jean Cayrol, e Hiroshima, mon amour, também de Alain Resnais, roteiro de Marguerite Duras, que se colocam diante deste desafio. Será dado destaque aos recursos de que se valem diretor e escritores, à potência criativa do entrelaçamento das imagens fílmicas e do texto literário, assim como a seu impacto político.

\section{ABSTRACT}

The Second World War, in its complexity and different dimensions, led to a reflection on the power (or powerlessness) of literature and the arts, questioning the limits of its representation in documentary records and works of art. In this essay, certain processes of construction of the narratives of Nuit et brouillard (1955), directed by Alain Resnais with a screenplay by Jean Cayrol, are compared to those of Hiroshima, mon amour, also by Alain Resnais, with a screenplay by Marguerite Duras, which stand before this challenge. Emphasis will be given to the resources used by directors and writers, to the creative power of intertwining filmic images and literary text, as well as their political impact.

\author{
PALAVRAS-CHAVE: \\ Nuit et brouillard; \\ Hiroshima mon amour; \\ Alain Resnais; \\ Jean Cayrol; \\ Marguerite Duras.
}

\section{KEYWORDS}

Nuit et brouillard;

Hiroshima mon amour;

Alain Resnais;

Jean Cayrol;

Marguerite Duras.

\footnotetext{
I Universidade Federal do Rio de Janeiro, Rio de Janeiro, Rio de Janeiro, Brasil.

II Apresento aqui os primeiros resultados do projeto de pesquisa Visões do outro e dos impérios; (não) adaptações de Salammbô de Flaubert para a ópera, desenvolvido com apoio do CNPq, com bolsa de produtividade em pesquisa. Processo n. 306918 /2019-6.
} 
Le soleil ni la mort ne se peuvent regarder fixement.

La Rochefoucauld

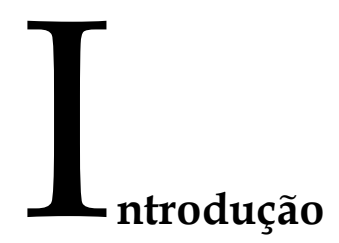

A escola de samba Águia de Ouro, da cidade de São Paulo, em seu desfile de carnaval de 2020, apresentou um enredo que tinha como tema o conhecimento humano, em seus aspectos positivos, mas também negativos. Um de seus carros alegóricos, que chamou a atenção do público, da imprensa e da população de modo geral e, em especial, da comunidade japonesa de São Paulo, representava a bomba atômica Little Boy que foi lançada por um bombardeiro americano sobre a cidade de Hiroshima, em 6 de agosto de 1945, matando 200 mil pessoas: "O terceiro carro lembrou o bombardeio de Hiroshima, no final 120 pessoas fizeram uma encenação sobre a devastação. Algumas delas eram parte da comunidade japonesa de SP" (G1 Globo, 2020a [s.p.]). O bombardeio e o massacre se repetiram na cidade de Nagasaki, no dia 9 de agosto de 1945. A respeito da representação deste episódio, que foi polêmica, a posição da comunidade japonesa em São Paulo foi de que "o carro suscitava lembranças ruins e tristes" (G1 Globo, 2020b [s.p.]).

Durante a Segunda Guerra Mundial, além das mortes de soldados em batalhas, foram sistemáticos os bombardeios de cidades, destroçando populações civis, foram promovidos extermínios em massa e genocídios foram programados e executados. Milhões de pessoas foram assassinadas. Holocausto. Populações inteiras foram espoliadas, estupradas, aterrorizadas e enxotadas, redistribuídas em outras terras, arrancadas de suas raízes. "Conflito algum registrado pela História matou tanta gente. Porém o mais impactante é o número de mortos entre os civis não combatentes: ao menos 19 milhões, ou seja, mais da metade do total" (JUDT, 2008, p. 31-2).

Era o Mal em uma escala ainda desconhecida da humanidade. A Paz foi imposta e celebrada com um pragmatismo que instalou tribunais, distribuiu medalhas de heroísmo e condenou alguns à morte, à prisão ou ao opróbio. Uma questão moral, entre muitas, foi colocada e ainda se coloca: as bombas lançadas sobre as cidades de Hiroshima e Nagasaki, que extinguiram duas cidades e decimaram sua população, deixando um 
rastro de sequelas entre os sobreviventes, ${ }^{1}$ foram justificadas por terem apressado o fim da guerra e teriam assim poupado milhões de vidas.

Uma questão interroga, igualmente, o campo das artes, desdobrando-se entre os valores morais e os limites da estética. O conflito mundial em sua complexidade e dimensões levou a uma reflexão sobre a (im)potência da literatura e das artes. O horror absoluto deve, pode ser contado pela escrita literária ou ser representado pelo cinema ou outros meios de expressão artística? Por que e como construir um objeto estético na distância que separa o acontecimento e a necessidade ou o desejo de o representar? Por que e como acolher a obra de arte que diz, mostra, dança ou canta a destruição? ${ }^{2}$

No Festival de Cannes de 1959, o filme Hiroshima, mon amour, do cineasta Alain Resnais (1922-2014), com roteiro de Marguerite Duras (19141996), coloca-se frente a esse desafio, dando forma, cor, movimento, melodia e ritmos à narração poética de uma história de amor que atravessa os registros da História. Será realizada neste ensaio uma comparação dos processos de construção de narrativas nos filmes Nuit et brouillard (1955) e Hiroshima, mon amour, ambos dirigidos por Alain Resnais, ressaltando os limites da representação documental, assim como a potência criativa das imagens fílmicas e do texto literário e seu impacto político.

\section{Do documentário à ficção}

Hiroshima, mon amour não é a primeira obra cinematográfica de Alain Resnais a representar uma incursão nos terrenos explosivos dos horrores daquela Guerra. Em 1956, fora exibido no Festival de Cannes o documentário Nuit et brouillard (Noite e neblina, 1955), do cineasta Alain Resnais. É um filme que dura 32 minutos, com texto do poeta e romancista Jean Cayrol (1911-2005), música composta pelo compositor austríaco Hanns Heisler e texto recitado pelo ator Michel Bouquet (1925-).

Curiosa categorização essa de documentário, como se documentar o horror, em uma escala tão gigantesca? Reproduzo abaixo a sinopse de Nuit et brouillard, quando de uma chamada recente para a exibição do filme pela RTP, Rádio e Televisão de Portugal, a qual evidencia o trabalho de colaboração entre cineasta e roteirista, e celebra seus resultados:

[...] Nuit et Brouillard continua a ser simplesmente o melhor filme alguma vez feito sobre os campos de concentração. Alain Resnais

\footnotetext{
${ }^{1}$ Grifos meus, para me distanciar destas falas.

2 Em uma enumeração não exaustiva, apenas no cinema, em seus mais variados gêneros, podemos citar Duas mulheres (1960), de Vittorio de Sicca, O porteiro da noite (1974), de Liliana Cavani, O casamento de Maria Braun (1979), dirigido por Rainer Werner Fassbinder, A vida é bela (1997), de Roberto Benigni, O resgate do soldado Ryan (1998), dirigido por Steven Spielberg e Bastardos inglórios (2009), de Quentin Tarantino. Em um suporte mais recente, o das séries em streaming, destacam-se O Pacífico (2010) e Hunters (2020).
} 
pesquisou durante quatro anos os materiais disponibilizados pela Commission d'Histoire de la Déportation, ${ }^{3}$ entidade que fez a encomenda do filme. A abundância de imagens disponíveis, pela sua carga emotiva, constituía em si mesma uma armadilha, visto apontar no sentido de uma denúncia já feita. Resnais, que conta aqui com a colaboração de Chris Marker, contornou essa dificuldade a partir de uma reflexão sobre esses materiais que é, ao mesmo tempo, uma reflexão sobre a memória e o esquecimento, como, aliás, acontece em todo o seu cinema. Acresce que o filme tem texto do grande escritor Jean Cayrol, ele próprio um ex-internado no campo de concentração de Mathausen e autor de Poèmes de la Nuit et Brouillard. Desta combinação de talento e experiência vivida resultou uma das obras-primas absolutas de toda a História do Cinema: Nuit et Brouillard. Nuit et Brouillard recebeu o Prémio Jean Vigo em 1956, o Grande Prémio do Cinema francês em 1956 e a medalha de ouro do festival de Karlovy Vary em 1957. (Nuit et brouillard; a evocação dos campos de concentração nazis. RTP; Radio e Televisão de Portugal, 2020)

Embora tendo lutado no movimento da Resistência e tendo sido preso pelos alemães em 1942, Jean Cayrol - que passou pela prisão de Fresnes e o campo de concentração de Gusen-Mauthausen e foi libertado em 1945 pelo exército americano -, não escrevera o poema-roteiro a partir de uma experiência pessoal dos campos de extermínio. Denunciado por fazer parte de uma rede de espionagem, Cayrol foi aprisionado no regime Nacht und Nebel (Noite e neblina), "destinado a fazer desaparecer o mais discretamente possível os resistentes" (DIATKINE, 1997, [s.p.]). ${ }^{4}$ A narração do filme é um poema em parte escrito no cativeiro, em parte composto a partir de registros fotográficos colocados à sua disposição, por Alain Resnais: "Em sua autobiografia Era uma vez, o escritor Jean Cayrol conta como pensou que fosse ficar 'louco', depois de ter prendido, nas paredes, as imagens do universo concentracionário" (Idem, [s.p.]).

O processo de montagem constrói uma estrutura de contraste entre a filmagem dos campos de concentração desertos, nas sequências iniciais e finais e as imagens por elas emolduradas. A abertura e a conclusão do filme, com as cores do presente, servem de moldura à reprodução de fotos e filmes ${ }^{5}$ em preto e branco, selecionados na imensa massa de imagens arquivadas, que são os documentos daquele passado recente. A montagem de cenas faz contrastar a pacífica beleza das paisagens campestres e o

\footnotetext{
${ }^{3}$ Em uma entrevista de 1955, Alain Resnais relata tratar-se de uma encomenda do Comitê da História da Segunda Guerra Mundial. Alain Resnais interview on 'Night and Fog'/'Nuit et Brouillard' (1955) [s.d.]. Disponível em: https://www.youtube.com/watch?v=oQ8JV07QgQQ, acesso em $11 / 3 / 2020$.

${ }^{4} \mathrm{~A}$ tradução das citações em francês são de minha responsabilidade.

${ }^{5}$ Mauro Luiz Rovai ressalta que Resnais utiliza inclusive sequências do filme de Leni Riefensthal, O triunfo da vontade, de 1934, "um filme que está em uma zona cinzenta entre o documentário e a propaganda" (2018, p. 5-6).
} 
horrendo recorte dos espaços edificados. Imagens, o comentário-narrativa e trilha sonora formam um jogo de contraponto. ${ }^{6} \mathrm{O}$ leitmotiv é o confronto expresso, desde as primeiras sequências do filme, pela anáfora ${ }^{7}$ même (até mesmo):

Même un paysage tranquille, même une prairie avec des vols de corbeaux, des moissons et des feux d'herbe, même une route où passent des voitures, des paysans, des couples, même un village pour vacances, avec une foire et un clocher, peuvent conduire, tout simplement, à un camp de concentration. ${ }^{8}$ (RESNAIS, 1955)

Um outro recurso poético é a enumeração dos campos, belas sonoridades enfileiradas em um rosário de dor: "Struthof, Oranienbourg, Auschwitz, Neuengamme, Belsen, Ravensbruck, Dachau, Mauthausen, foram nomes como os outros, nos mapas e nos guias de viagem" (Idem, 1955). Cenários vazios, "visitados apenas por uma câmera” (Idem, 1955), personificação de um objeto que faz do espectador um visitante em lugares onde há apenas construções abandonadas. São evocados, por uma trilha sonora que entrelaça música e narração, os milhões de prisioneiros que lá foram mortos. O comentário é pontuado por reflexões sobre o que pode ser ainda visto e mostrado. Cayrol recorrerá às metáforas, as imagens do presente são apenas "restos", "a casca" (Idem, 1955). Nas sequências finais, a impossibilidade de filmar o fantasmagórico e de documentar o Holocausto é explicada por Michel Bouquet com uma entonação monótona, que se aproxima do recitativo: "Nove milhões de mortos assombram esta paisagem" (Idem, 1955).

Se cinema é movimento (movie), como documentar espaços destruídos, cadáveres amontoados em valas, sobreviventes esquálidos, a rigidez dos fornos e alojamentos, a crueldade dos experimentos médicos, o projeto de erradicação sistemática de certos grupos? O humano desapareceu das paisagens pacificadas do presente, em que só a câmera se move, enquanto vemos, nos registros do passado, a movimentação das

\footnotetext{
6 "Contraponto. (lat. contra $=$ diante de, face a face; punctum =picada) 1. Técnica musical que consiste em superpor várias 'vozes', cada uma conservando sua autonomia melódica e, contudo, contribuindo para formar um conjunto harmonioso. 2. [...] o termo se refere a um procedimento semântico fundamentado no contraste ou na conjunção de elementos distintos, notadamente duas intrigas que se entrelaçam" (GORP et alii, 2005, s.v. Contrepoint, p. 118).

7 "Anáfora. Do grego anafora (ana-ferw): levantar, levar para cima, puxar para si, e, por extensão, oferecer, relatar, narrar, rememorar, imputar algo a alguém. O termo é utilizado em várias acepções. No ritual litúrgico cristão, designa a parte central da celebração eucarística, o cânone, no decurso do qual o celebrante rememora a Última Ceia de Jesus com os seus discípulos. Na retórica, designa a figura que consiste na repetição de um mesmo termo no início de várias frases, criando assim um efeito de reforço e de coesão textual" (RODRIGUES, 2009 [s.p.]).

8 "Até mesmo uma paisagem tranquila, até mesmo uma pradaria com vôos de corvos, colheitas e fogueiras de grama, até mesmo uma estrada em que passam carros, camponeses, casais, até mesmo um vilarejo para férias, com uma feira e um campanário, podem levar simplesmente a um campo de concentração" (cf. A íntegra do comentário em CAYROL, [s.d.] [s.p.]).
} 
tropas alemãs, dos deportados, e sobretudo dos trens. Este último recurso será amplamente retomado por Claude Lanzmann (1925-1918), em Shoah (1985), documentário realizado a partir de depoimentos de sobreviventes dos campos de extermínio, entrevistas com ex-oficiais nazistas e maquinistas dos "trens da morte" (DVD Shoah [s.d.] [s.p.]). O filme, em sua insuportável duração de 543', evidencia, se ainda necessário fosse, a impossibilidade de documentar o irrepresentável.

Nuit et brouillard responde a uma demanda de caráter político, dever de memória e advertência: "[...] a guerra adormeceu, um olho sempre aberto" (RESNAIS, 1955). Resulta em uma obra de arte que provoca uma reflexão sobre o poder e os limites das imagens e das palavras, quando o humano se defronta com seus abismos. O processo de escrita e a montagem do filme, além do contraste entre passado e presente, apontam para uma dupla inscrição, o registro dos documentos visuais e a evocação poética da "máquina" montada pelos nazistas, metáfora reificadora, a suprimir a humanidade dos carrascos. Os recursos fílmicos e literários desta narrativa cinematográfica serão retomados alguns anos depois por Alain Resnais e Marguerite Duras em Hiroshima mon amour.

\section{Pontuações e contrapontos}

Hiroshima mon amour intensifica o mesmo entrelaçamento entre palavra, música e imagem, narrativa poética e documentos visuais, levando-os aos limites da representação. $O$ desafio da inscrição de memória com que se defrontam o cinema e a literatura volta-se para o episódio da bomba atômica jogada sobre Hiroshima e a destruição e o genocídio que apressaram o fim da guerra. A opção estética e a colaboração entre cineasta e escritor se repetem, desdobrando-se o impossível documentário na ficção de uma história de amor. O filme se voltará para uma narrativa em que são igualmente marcantes os recursos da criação poética.

Para Mauro Luiz Rovai, pesquisador da USP, Nuit et brouillard e Hiroshima mon amour, este é o primeiro longa-metragem de Resnais após dez anos filmando apenas documentários, fariam parte de "um conjunto no interior do qual as obras dialogam entre si, colaborando para caracterizar o universo temático pelo qual Resnais ficaria conhecido [...] em que se destacam a morte, a memória e os modos de lidar com ela" $(2018$, p. 3). Não se trata apenas do mesmo universo temático e do mesmo dever ético de memória, mas também da experimentação de novos modos, tanto no cinema quanto na literatura, de representar horrores até então inimagináveis. 
Desde o Surrealismo e Jean Cocteau (1889-1963), os romancistas se sentem atraídos pelo cinema (CLOUZOT, 1972, p. 46-80). ${ }^{9}$ Nos anos que se seguem à Segunda Guerra Mundial, um pequeno grupo de escritores e cineastas procuram uma escritura fílmica análoga à escrita literária. Neste grupo encontramos Alain Resnais, Agnès Varda (1928-2019), Chris Marker (1921-2012), Alain Robbe-Grillet (1922-2008), Marguerite Duras, Jean Cayrol, Claude Durand (1938-2015) e Henri Colpi (1921-2006). Residentes da Rive Gauche de Paris, 10 são chamados pelos críticos de Grupo Rive Gauche. Em sua maioria haviam lutado contra os nazistas na Resistência francesa, interessam-se pelos problemas mundiais, militam em movimentos de esquerda, pela paz e contra toda forma de opressão. Em um contexto de guerras de descolonização, ${ }^{11}$ denunciam o fascismo, 0 racismo e o colonialismo. ${ }^{12}$ Suas obras se veem, então, às voltas com a censura.

Uma foto do campo de Pithiviers em que aparece um guarda francês, identificado enquanto tal por seu quépi, quase impede a exibição de Nuit et brouillard pela comissão de censura. O filme é liberado após ter sido coberto o tal quépi. Incomoda mais as autoridades francesas o registro da colaboração do Governo de Vichy ${ }^{13}$ com a política nazista de deportação, do que a máquina de extermínio nazista, o que foi comentado por Resnais, nos seguintes termos:

Ah ben ça on ne s'en était jamais douté! [...] Ça c'est extraordinaire! [...] On ne l'avait pas vu, on ne l'avait pas vu ce gendarme! [...] D'ailleurs au dos de la photo il y avait l'Aigle allemand et autorisé par le Kommandantur ou quelque chose comme ça, ce qui était formidable. La France interdisait un document qui avait éte autorisé par les nazis. [...] Moi j'ai refusé de le couper sans une lettre et eux [a Comissão francesa de controle] disaient: "Et bien non, si vous ne coupez pas de votre propre chef, et bien on vous coupe les dix dernières minutes." [...] Drôle d'époque... [...] Et en plus personne n'aurait repéré ce gendarme [...] Alors on a transigé, dans l'intérêt tout de même... [...] Alors on a transigé sur cette chose incroyable, on a peint une poutre sur le quépi

\footnotetext{
9 As informações que seguem retomam e atualizam pesquisa realizada para minha tese de doutoramento, Marguerite Duras; o texto e sua travessia (MELLO, 1985, p. 20).

${ }^{10}$ Bairros da margem esquerda do rio Sena.

11 Processo de emancipação política dos países colonizados, desencadeado ao término da Segunda Guerra Mundial. No que se refere ao Império colonial da França, destacamos a perda de seus mandatos na Síria e no Líbano em 1945, a derrota militar de Dien Bien Phu na Indochina, em 1954, e a longuíssima guerra da Argélia por sua independência (1954-1962).

${ }^{12}$ Registramos a este repeito o filme de Chris Marker e Alain Resnais, Les statues meurent aussi (1953), documentário sobre a arte africana, que após ser exibido no Festival de Cannes foi retirado de circulação comercial por ter sido considerado anticolonial. A segunda metade do filme foi censurada até 1963 e sua versão integral só pode ser exibida publicamente, a partir de 1968 (RESNAIS, 1969).

${ }^{13}$ Regime de exceção, liderado pelo Maréchal Pétain, com sede na cidade de Vichy, que governou a França e seu império colonial, de 1940 a 1944, fazendo deste país um Estado cliente que colabora com a Alemanha nazista.
} 
du gendarme. Alors le gendarme est là mais on ne peut pas distinguer très bien son quépi. ${ }^{14}$ (RESNAIS, [s.d] 2'28"'-4'17")

E por razões diplomáticas, para não prejudicar os projetos de cooperação entre a França e a Alemanha dos anos 1950, no cenário do que foi chamado de política de reconciliação, o filme não faz parte da mostra oficial do Festival de Cannes. Foi exibido em mostra paralela e proibido na Suíça, que alegou sua neutralidade. Apenas em 1997, o quépi foi restaurado. Hoje o filme já pode ser visto na Suíça... (cf. SIMÉONE, 2015 [s.p.]; DELAGE, 2003, p. 82).

Hiroshima mon amour vai igualmente se defrontar com a censura e provocar mal-estar diplomático. O filme é retirado da mostra oficial do Festival de Cannes de 1959 e é projetado em mostra paralela, desta vez a pedido da delegação americana. Terá cenas cortadas no Canadá e na Itália, sob pretexto de sexo e violência. Contudo, obtém o Prêmio da Crítica internacional (cf. MICHEL, 1997, p. 304).

A sinopse do filme não pode se limitar a mencionar uma aventura extraconjugal entre uma atriz francesa e um arquiteto japonês, com seu duplo apelo erótico e exótico. A escolha do ator procura evitar o carimbo étnico: "O ator japonês Eiji Okada é selecionado por Resnais que o viu atuar em um filme em Paris. Ele é o ator perfeito. Seu tipo físico não é marcado demais. Resnais não quer lançar mão do exotismo no amor dos dois amantes" (FATTEBERG, 2018 [s.p.]). Tampouco nos é oferecido o clichê do confronto de culturas, oriental e ocidental, francesa e japonesa, mas um concerto no sofrimento. O homem, Lui (Ele), afirmando que nada pode ser visto do que aconteceu na cidade de Hiroshima e a mulher, Elle (Ela), relembrando seu amor proibido por um soldado alemão e a punição que sofreu, no momento da depuração, são recursos que enfatizam o desalinhamento entre o registro documental e as marcas subjetivas das consequências do conflito.

Nuit et Brouillard já levara Resnais a uma reflexão sobre a armadilha do documento visual:

[...] é com uma grande humildade que ele se implicou na aventura ética e estética que fará de Nuit et Brouillard um filme inaugural em muitos aspectos. Uma de suas maiores contribuições vem da aguda reflexão que o inspira sobre a

14 “Ora nunca havíamos imaginado isto! [...] É extraordinário! [...] Não havíamos visto esse policial! [...] Aliás, no verso da foto, havia a Águia alemã e a autorização do Kommandantur ou algo parecido, o que era fantástico. A França proibia um documento que havia sido autorizado pelos nazistas. [..] Eu recusei cortar a cena sem uma carta e eles [a Comissão de Controle francesa] diziam: 'Ora não, se o senhor não cortar a cena por sua própria iniciativa, vamos cortar os dez minutos finais.' [...] Época bizarra...[...] E além disso ninguém teria visto esse policial [...] Então fizemos um acordo, pensando no interesse... [...] Então fizemos um acordo sobre essa coisa incrível, pintamos uma viga por cima do quépi do guarda. Então o guarda está lá, mas não se pode ver bem o quépi". 
armadilha da evidência do visível, e mais ainda do voyeurismo como modo ordinário de confrontação da história. Este procedimento levará, três anos mais tarde, ao encontro com Marguerite Duras e à escritura de Hiroshima mon amour. (DELAGE, 2003, p. 91)

Antoine Dauman (1925-1998), produtor de Nuit et Brouillard, solicita a Resnais um documentário sobre a bomba atômica, que abandona este primeiro projeto e busca a colaboração de Marguerite Duras, com a proposta da ficção de uma história de amor. Em carta a Duras, Resnais lhe pede: "Faça literatura, esqueça a câmera" (FATTEBERG, 2018 [s.p.]).

$\mathrm{O}$ título do filme, que é um oximoro, ${ }^{15}$ expressa a um só tempo a necessidade e a inadequação destes filmes; sua construção paradoxal atesta o confronto entre a impossível inscrição histórica e as feridas subjetivas da Segunda Guerra Mundial. O texto de Marguerite Duras é um poema elegíaco, canto de lamento da perda da liberdade, de uma paixão, de vidas.

Hiroshima mon amour é do mesmo modo comparável a uma ópera, que associa cinema, literatura e música ${ }^{16}$. Em uma entrevista concedida ao crítico de cinema Michel Ciment (1838-), Alain Resnais explica seu desejo de realizar uma ópera filmada, que fosse contemporânea: « J'ai toujours eu envie de faire un opéra filmé, mais à la condition évidemment que cet opéra soit écrit par un musicien contemporain, enfin vivant, qu'il l'écrive comme un scénariste l'écrirait en sachant que c'est pour le cinéma qu'il travaille »(2006, $\left.0^{\prime} 34^{\prime \prime}-0^{\prime} 53^{\prime \prime}\right) .{ }^{17}$

Temos, no filme, o roteiro de Marguerite Duras, ou seja, seu libretto, a ambientação em diferentes cenários, as árias cantadas pelo casal, a compor a representação da tragédia vivida por eles e rememorada no encontro amoroso. $\mathrm{O}$ dueto entre Ele e Ela pode ser aproximado do recitativo ${ }^{18}$, com um ritmo artificialmente lento e sincopado, desde as primeiras falas dos atores: «Lui: Tu n'as rien vu à Hiroshima. Rien ». Ao que

15 “Oxímoro. Na retórica, consiste na combinação e expressão de vocábulos paradoxais. Aproxima-se da antítese, porém no oxímoro ambos os termos se excluem, a fim de revelar que a conciliação de contrários é possível e, por vezes, indispensável para se exprimir a verdade. [...] Poder-se-á considerar este recurso estilístico como uma "antítese lexical”, isto é, o objectivo do oximoro é intensificar, ainda mais do que antítese, a junção paradoxal, vincando que o confronto de duas palavras ou ideias opostas e incongruentes permite valorizar a força expressiva [...]" (SERRA, 2009 [s.p.]).

16 A música do filme é uma composição de Georges Delerue (1925-1992) e Giovanni Fusco (19061968).

17 “Sempre desejei fazer uma ópera filmada, mas evidentemente com a condição de que esta ópera fosse escrita por um músico contemporâneo, vivo, que fosse escrita como a escreveria um roteirista, sabendo que está trabalhando para o cinema".

18 "RECITATIVO. MUS. Na música dramática (cantata, ópera, oratório) e a música vocal religiosa e profana moderna (moteto, melodia, 'Lied') canto livremente declamado, cuja linha melódica e desenho rítmico acompanham as inflexões naturais da frase falada. [...] Por analogia. Parte de uma obra instrumental cuja função é descritiva ou dramática" (TRÉSOR DE LA LANGUE FRANÇAISE. s.v. Récitatif). 
Ela responde: "J'ai tout vu. Tout »19 (Hiroshima mon amour's Unforgettable opening, 2015, 1'18"-1'23").

O historiador do cinema David Bordwell, ao analisar as primeiras sequências de seu prólogo de 13 minutos, observa que Hiroshima traz para o espectador um novo modo de olhar, que traduz a inadequação de uma imagem visual, a impossibilidade de se ver o que ocorreu em Hiroshima ("the film insists on the inadequacy of witnessing anything", 2018, 2'30"). Se nada foi visto, como pode ser rememorado? Bordwell destaca o processo de montagem, que me parece muito próximo da técnica pictórica da colagem, ao justapor o abraço erótico do casal, os corredores do hospital de Hiroshima, as escadarias do museu que conserva a memória subjetiva das vítimas, e até mesmo uma "recriação ficcional do ataque" reconstituído com figurantes. (2018, 1'58"-2'26"). As cenas são acompanhadas pelo diálogo em quiasmo ${ }^{20}$ entre o arquiteto e a enfermeira, ritmado por repetições:

- Ainsi l'hôpital, je l'ai vu. J'en suis sûre. L'hôpital existe à Hiroshima. Comment aurais-je pu éviter de le voir?

- Tu n'as pas vu d'hôpital à Hiroshima. Tu n'as rien vu à Hiroshima.

- Quatre fois au musée.

- Quel musée à Hiroshima?

- Quatre fois au musée, à Hiroshima. [...] Les gens se promènent pensifs à travers les photographies, les reconstitutions, faute d'autre chose. Les photographies, les photographies faute d'autre chose. ${ }^{21}$ (Hiroshima mon amour's Unforgettable opening, 2015, 1'25"-2'52")

No museu, pedaços de ferro retorcidos e incinerados pelo calor, que se tornaram objetos estéticos: "J'ai vu des capsules en bouquet. Qui l'aurait pensé? »22 (Idem, 3'20"-3'25"). Além do ritmo, do refrão e das repetições, algumas rimas são a marca sonora, clara e didática do poema, como bouquet-pensé (buquê-imaginado). E o jogo de contraponto das imagens continua, entre a pele conservada fresca, a pedra queimada, longos cabelos. Um filme, fotografias, explicações "já que não há mais nada".

Como aquilo que ocorreu em Hiroshima, a história do homem e a história da mulher têm que ser reconstituídas fragmento por fragmento,

\footnotetext{
19 "Ele: - Você nada viu em Hiroshima. Nada" "Ela: - Eu vi tudo. Tudo."

20 "QUIASMO. Do grego Khiasmus, «cruzamento», é uma figura de estilo que se traduz pela inversão da ordem das palavras (o que poderá conduzir à repetição das mesmas) e de duas frases que se opõem, permitindo não só diversificar o ritmo frásico, bem como levar à obtenção de certos efeitos semânticos, a partir da posição que as palavras ocupam no enunciado" (ROCHA, 2009 [s.p.]).

21 " - Assim eu vi o hospital, eu vi. Tenho certeza. O hospital existe em Hiroshima. Como poderia deixar de vê-lo?/ - Você não viu hospital em Hiroshima. Você nada viu em Hiroshima./ Quatro vezes ao museu./ -Que museu em Hiroshima?/ -Quatro vezes o museu, em Hiroshima. [...] As pessoas passeiam pensativas, passam pelas fotografias, as reconstituições, já que não há mais nada. As fotografias, as fotografias, já que não há mais nada".

22 "Vi buquês de tampas de garrafa. Quem teria imaginado?"
} 
em uma narrativa feita de justaposições, construção paratática, com leves deslocamentos, em que passo a passo se engendram a anamnese do passado e o resultado catártico de um trabalho de luto. ${ }^{23}$ A construção do poema ecoa na montagem do filme. É o presente que recriará o passado, trazendo a coleção de suas imagens para o nível da simbolização.

$O$ relato dela faz surgir documentadas cenas da violência da depuração que, no momento da libertação da França, responde à violência que havia sido a ocupação nazista: mulheres arrastadas, os cabelos raspados, humilhação, expostas ao opróbio, por terem se relacionado com o inimigo alemão. $\mathrm{O}$ ódio dos homens se descarrega, de um modo cego e covarde, em um dos entes mais frágeis de sua cultura. A este ódio se contrapõe a apaixonada união do presente e do passado.

O filme das imagens e o filme das vozes se entrelaçam, na enumeração do que não pode ser mostrado, hipotipose. ${ }^{24} \mathrm{O}$ fio do presente é tecido na imagem do encontro dos corpos e no canto das vozes, levando ao desenlace de uma cura simbólica; os amantes se renomeiam, Ele será Hiroshima e Ela, Nevers. Despojados de sua cultura, roupas e identidades, Ele e Ela fusionam a destruição de Hiroshima e a experiência mais íntima que, na cidade de Nevers, esmagou, em nome da pátria a liberdade da mulher na escolha de seu parceiro. No jogo da rememoração, o homem japonês e o jovem soldado alemão se confundem. Não são representantes de um povo, uma cultura ou uma etnia, não são o outro, o inimigo, alguém que deva ser destruído, mon amour.

\section{Considerações finais}

A Segunda Guerra Mundial traz para os artistas, escritores, cineastas, fotógrafos, compositores, o desafio de novos modos de registro de memória, face aos limites do documento. Como produzir um objeto estético, monumento à memória das mortes, da destruição e dos abismos de horror, em um mundo pós-guerra? A necessidade de criar obrasmemória dando conta dos registros documentais do acontecimento e de suas marcas subjetivas leva à colaboração entre cineastas e poetas. Nuit et brouillard e Hiroshima mon amour são aclamados pela crítica e pelo público, como duas obras primas, respectivamente, do documentário e do longametragem de ficção. Nos dois filmes dirigidos por Alain Resnais, os documentos visuais, paradoxalmente oferecidos ao espectador $\mathrm{e}$ descartados por sua insuficiência, vêm recobertos pela poesia de Jean Cayrol e Marguerite Duras, em uma concepção neoplatônica do cinema. $\mathrm{O}$

${ }^{23}$ Cf. este processo no que se refere à pintura em LEENHARDT, 2000, p. 77-9.

24 "Descrição, dinâmica e animada de uma pessoa, coisa ou acção, em regra ausente no momento da descrição, mas cuja presença é assumida de forma fantástica. [...] O artifício é bastante usado sobretudo em memórias e celebrações de entes queridos que partiram, de lugares que se visitaram outrora, de coisas que trazemos à realidade ilusória do presente mas que pertencem à realidade passada" (CEIA, 2009, s.v. Hipotipose). 
registro documental é incapaz, qualquer pretensão a uma estética realista seria falha. Em Hiroshima mon amour, ópera da Segunda Conflagração Mundial, Marguerite Duras leva a linguagem cinematográfica para além do que fora realizado por Resnais, em Nuit et brouillard. Neste filme, são tecidos o fio de uma cidade inteira e sua ponta mais subjetiva. À literatura e ao cinema, a poesia vem lembrar que face ao que foge à significação ou escapa a ser representado, ergue-se o significante poético. O homem e a mulher, que viveram e se tornaram Hiroshima e Nevers, podem se curar de seu passado pela palavra, meu amor.

\section{Referências bibliográficas}

BORDWELL, David. "Mutations on memory". In: Hiroshima mon amour. Observations on Film Art, n. 23. The Criterion channel: 2018. Disponível em: https://www.criterion.com/current/posts/5940-mutations-of-memoryin-hiroshima-mon-amour, acesso em: 30/3/2020.

CAYROL, Jean. "Texte de Jean Cayrol sur les camps". In: Patrimoine, Mémoire et Histoire [s.d.] [s.p.]. Disponível em:

https://pmhdieulefit.org/fr/ressources-en-ligne/texte-de-jean-cayrolsur-les-camps/, acesso em: 18/3/2020.

CEIA, Carlos. "Hipotipose”. In: CEIA, Carlos (org.). E-Dicionário de termos literários (EDTL). Lisboa: 27 dez. 2009. Disponível em: https://edtl.fcsh.unl.pt/encyclopedia/prefix:hip/page/2/, acesso em: 6/4/2020.

CLOUZOT, Claire. "Le groupe Rive Gauche. Le cinéma des auteurs". In: Le cinéma français depuis la nouvelle vague. Paris: Fernand Nathan \& Alliance Française, 1972, p. 46-80.

DELAGE, Christian. "Nuit et Brouillard: un tournant dans la mémoire de la Shoah". Politix, v. 16, n. 61, 2003, p. 81-94. Disponível em: https://www.persee.fr/doc/polix_0295-2319_2003_num_16_61_1257, acesso em: 24/3/2020.

DIATKINE, Anne. "Première publication du commentaire de Jean Cayrol pour le film de Resnais et des poèmes de Mauthausen". Libération. Mots de nuit et de brouillard, 16-1-1997 [s.p.]. Disponível em:

https://next.liberation.fr/livres/1997/01/16/mots-de-nuit-et-debrouillard-premiere-publication-du-commentaire-de-jean-cayrol-pour-lefilm-de-res_193940, acesso em 10/3/2020.

FATTEBERG, Catherine. Hiroshima mon amour. RTS Culture janvier: 2018 [s.p.]. Disponível em:

https://www.rts.ch/info/culture/ cinema/9252366-hiroshima-monamour.html, acesso em: 22/3/2020. 
G1 GLOBO. "Águia de Ouro mostra lado bom e ruim da sabedoria, da invenção da roda à bomba atômica". Carnaval 2020 em São Paulo. 2020a [s.p]. Disponível em:

https://g1.globo.com/sp/saopaulo/carnaval/2020/noticia/2020/02/23/aguia-de-ouro-mostra-ladobom-e-ruim-da-sabedoria-da-invencao-da-roda-a-bomba-atomica.ghtml, acesso em: 3/3/2020.

G1 GLOBO. “Águia de Ouro diz que referência a Hiroshima e Nagasaki em desfile da escola foi respeitosa e sem insulto ou difamação". Carnaval 2020 em São Paulo. 2020b [s.p.]. Disponível em:

https://g1.globo.com/sp/saopaulo/carnaval/2020/noticia/2020/02/25/apos-polemica-aguia-deouro-diz-que-referencia-a-hiroshima-e-nagasaki-em-desfile-da-escola-foirespeitosa-e-sem-insulto-ou-difamacao.ghtml, acesso em: 13/3/2020.

GORP, van Hendrik; DELABASTITA, Dirk; D'hulst LIEVEN; GHESQUIERE, Rita; GRUTMAN, Rainier; LEGROS, Georges. Dictionnaire des termes littéraires. Paris: Honoré Champion, 2005.

INSTITUTO MOREIRA SALES. Shoah, [s.d.] [s.p.]. Disponível em: https://lojadoims.com.br/product/31051/dvd-shoah, acesso em: 18/3/2020.

JUDT, Tony. Pós-guerra: uma história da Europa desde 1945. Trad. de José Roberto O'Shea. Rio de Janeiro: Objetiva, 2008.

LEENHARDT, Jacques. "A impossível simbolização 'daquilo que foi'". Tempo Social; Revista de Sociologia USP. São Paulo, 12 (2): 75-84, novembro de 2000. Disponível em:

https://doi.org/10.1590/S0103-20702000000200007, acesso em: $31 / 3 / 2020$.

LE TRÉSOR DE LA LANGUE FRANÇAISE - Atilf. Lorena: Université de Lorraine, [s.d]. Disponível em: http://www.atilf.fr/tlfi, acesso em: $4 / 4 / 2020$.

MELLO, Celina Maria Moreira de. Marguerite Duras; o texto e sua travessia. Tese de Doutorado em Semiologia. Rio de Janeiro: Universidade Federal do Rio de Janeiro; Faculdade de Letras, 1985.

MICHEL, Marie. "Hiroshima, mon amour." In: RAPP, Bernard; LAMY, Jean-Claude. Dictionnaire mondial des films. Paris: Larousse, 1997, p. 304.

RESNAIS, Alain. Nuit et Brouillard (1955). Disponível em: https://www.youtube.com/watch?v=CPLX8U2SHJE, acesso em: 3/3/2020.

RESNAIS, Alain. Alain Resnais interview on 'Night and Fog' /'Nuit et Brouillard' (1955). Disponível em:

https://www.youtube.com/watch?v=oQ8JV07QgQQ, acesso em: 11/3/2020.

RESNAIS, Alain. Alain Resnais à propos de l'interdiction du film "Les statues meurent aussi ». INA: 1969, 4'34". Disponível em: 
https://www.ina.fr/audio/P12123747, acesso em: 26/3/2020.

RESNAIS, Alain. Alain Resnais à propos de sa prédilection pour les voix des comédiens. INA: 2006, 2’54". Disponível em:

https://www.ina.fr/audio/P12124755, acesso em: 4/4/2020.

ROCHA, Ana Paula. "Quiasmo." In: CEIA, Carlos (org.) E-Dicionário de termos literários (EDTL). Lisboa: 24 dez. 2009, [s.p]. Disponível em: https://edtl.fcsh.unl.pt/encyclopedia/quiasmo/, acesso em: 5/4/2020. RODRIGUES, Adriano Duarte. "Anáfora." In: CEIA, Carlos (org.). EDicionário de termos literários (EDTL). Lisboa: 29 dez. 2009, [s.p.]. Disponível em: https://edtl.fcsh.unl.pt/encyclopedia/anafora/, acesso em: 21/3/2020.

ROVAI, Paulo Luiz. "Formas de manifestação do passado em filmes de Alain Resnais; aproximações sociológicas". Revista Brasileira de Ciências Sociais, v. 33, n. 96 /2018: e339615, p. 1-15. Disponível em: https://doi.org/10.17666/339615/2018, acesso em: 15/3/2020.

RTP (Radio e Televisão de Portugal). Nuit et brouillard: a evocação dos campos de concentração nazis. Lisboa: RTP, 2020, [s.p.]. Disponível em: http://www.rtp.pt/programa/tv/p13501, acesso em: 6/3/2020.

SERRA, Carlos. "Oxímoro". In: CEIA, Carlos (org.). E-Dicionário de termos literários (EDTL). Lisboa; 24 dez. 2009, [s.p.]. Disponível em: https://edtl.fcsh.unl.pt/encyclopedia/oximoro/, acesso em: 19/3/2020.

SIMÉONE, Christine. "Nuit et Brouillard » d'Alain Resnais, une mémoire pour demain. InterFranc, 22/01/2015, [s.p.]. Disponível em: https://www.franceinter.fr/culture/nuit-et-brouillard-d-alain-resnais-unememoire-pour-demain, acesso em: 19/3/2020.

THE CRITERION COLLECTION. Hiroshima mon amour's unforgettable opening. 27 jul. 2015, 4'29". Disponível em: https://www.criterion.com/current/posts/3640-hiroshima-mon-amours-unforgettable-opening, acesso em: 5/4/2020.

Recebido em 26 de maio de 2020

Aprovado em 27 de maio de 2020

Celina Maria Moreira de Mello é professora titular de Letras Francesas da Universidade Federal do Rio de Janeiro e bolsista de produtividade em pesquisa do CNPq. Docente permanente do Programa de pós-graduação em Letras Neolatinas da mesma universidade. Publicou A literatura francesa e a pintura (2004) e organizou, juntamente com Pedro Paulo Garcia Catharina e Sonia Cristina Reis, A palavra, o artista e a leitura: homenagem a Théophile Gautier (2014). Contato: celina.mello@pq.cnpq.br

ORCiD: https:// orcid.org/0000-0002-1829-0187 